\title{
Histochemical Changes in the Cerebellum of Wistar Rats Administered with Oral Doses of Zidovudine
}

\author{
Aniekan Imo Peter ${ }^{1, ~ *, ~ G a b r i e l ~ J o s e p h ~ E k a n d e m ~}{ }^{1}$, Anozeng Oyono Igiri ${ }^{2}$, Moses Bassey Ekong ${ }^{1}$, \\ Dianabasi King Udoh ${ }^{3}$
}

${ }^{1}$ Department of Anatomy, University of Uyo, Uyo, Nigeria

${ }^{2}$ Department of Anatomy, University of Calabar, Uyo, Nigeriap

${ }^{3}$ Chemical Pathology Unit, Med Lab Services, University of Uyo Teaching Hospital, Uyo, Nigeria

\section{Email address:}

aniekanpeter@uniuyo.edu.ng (A. I. Peter)

\section{To cite this article:}

Aniekan Imo Peter, Gabriel Joseph Ekandem, Anozeng Oyono Igiri, Moses Bassey Ekong, Dianabasi King Udoh. Histochemical Changes in the Cerebellum of Wistar Rats Administered with Oral Doses of Zidovudine. American Journal of Bioscience and Bioengineering.

Vol. 3, No. 3, 2015, pp. 17-21. doi: 10.11648/j.bio.20150303.11

\begin{abstract}
Zidovudine is a drugs used in the management of Human Immunodeficiency Virus (HIV) and Acquired Immunodeficiency Syndrome (AIDS) infection in sub-Saharan Africa in combination with other drugs. The objective of this research was to investigate the potential harmful effects of this drug on the histology of the cerebellum of Wistar rats. Twenty male Wistar rats were used for this study. The rats were divided into 2 groups of 10 rats each. Group A served as the control and was administered with $1 \mathrm{ml}$ of distill water, while group B was administered with $8.57 \mathrm{mg} / \mathrm{kg}$ of zidovudine daily for 30 days, after which the rats where sacrificed and each cerebellum was harvested, processed and stained using haematoxylin and Eosin (H/E), silver impregnation method. Paraffin impregnated Glial Fibrilar Acidic Protein (GFAP), Neuron Specific Enolase (NSE) and Neurofilament (NF) immunochemistry methods. Stained slides were viewed using light microscope. Results showed that, the cerebellum of Groups B animals were affected with moderate to severe shrinking and distortion of the Purkinje cells and granular cells, when compared with the control. Group B animals, also showed more expression of GFAP, NSE and NF staining in their cerebellum than the control. This suggests that zidovudine is harmful to the cerebellum and should be taken with caution.
\end{abstract}

Keywords: Zidovudine, Cerebellum, Human Immunodeficiency Virus

\section{Introduction}

Zidovudine (ZDV) is a nucleoside analog reversetranscriptase inhibitor (NRTI), a type of antiretroviral drug used for the treatment of HIV/AIDS infection. It is a therapeutic analog of thymidine. ZDV was the first U.S. government approved treatment for HIV therapy, prescribed under the names RETROVIR and RETROVIS. ZDV was the first breakthrough in AIDS therapy, significantly reducing the replication of the virus in patients and leading to clinical and immunologic improvements [1-3]. It can also be used to prevent HIV transmission, such as from mother to child. When used as monotherapy in HIV-infected patients, ZDV safely slows HIV replication in patients, but generally does not stop it entirely [4]. The effectiveness of ZDV in the treatment of HIV infection is due to its selective affinity for HIV reverse transcriptase as opposed to human DNA polymerases [5, 6].

Zidovudine is a white to beige, odourless, crystalline solid with a molecular weight of 267.24 and a solubility of $20.1 \mathrm{mg} / \mathrm{mL}$ in water at $25^{\circ} \mathrm{C}$. The molecular formula is $\mathrm{C}_{10} \mathrm{H}_{13} \mathrm{~N}_{5} \mathrm{O}_{4}$. Zidovudine has been found effective, at high doses, in slowing the progression of AIDS dementia, and can penetrate the blood - brain barrier [7]. There are anecdotal reports of psychiatric symptoms, including mania and depression, in patients treated with zidovudine. Several case reports document manic episodes in association with zidovudine treatment, even in patients with no previous psychiatric history [8]. The mechanism involved in zidovudine - associated psychiatric effects are unknown. ZDV has been associated with seizures, particularly in cases of overdose, which have on rare occasions been fatal [9]. ZDV is well absorbed and extensively distributed, with peak serum concentration occurring within 0.5 to 15 hours [10].

Most of the studies of the toxicity of zidovudine in animal models were performed in mice, and as in humans, the most frequently cited effect, after either short-term or long-term 
dosing involved the haematopoietic system [11-17]. Olivero et al 1997 reported that transplacental exposure of mice to zidovudine at $25 \mathrm{mg} /$ day by gavage during the last third of gestation resulted in shorter chromosomal telomeres in the liver and brain of most newborn mice [18]. Despite these adverse effects, there is dearth of literature on the histological effect of this drug on the cerebellum. The objective of this work therefore was to investigate the histopathological changes in the cerebellum of Wistar rats administered with Zidovudine.

\section{Methodology}

Twenty male Wistar rats were used for this study. The rats were divided into 2 groups of 10 rats each. Group A served as the control and group B was the treatment group and was administered with $8.57 \mathrm{mg} / \mathrm{kg}$ of zidovudine. The animals were handled according to the guidelines for the treatment of laboratory animals. Ethical approval was from the Graduate School Committee University of Uyo. The rats were treated for 30 days and allowed water and feed ad libitum. On the $31^{\text {st }}$ day, the rats were sacrificed using chloroform inhalation method and their cerebellum harvested, processed and stained using the Haematoxylin and Eosin, Silver impregnation method, paraffin impregnated Glial Fibrilar Acidic Protein (GFAP), Neuron specific Enolase (NSE) and Neurofilament (NF) immunochemistry methods. Stained slides were viewed using light microscope.

\section{Results}
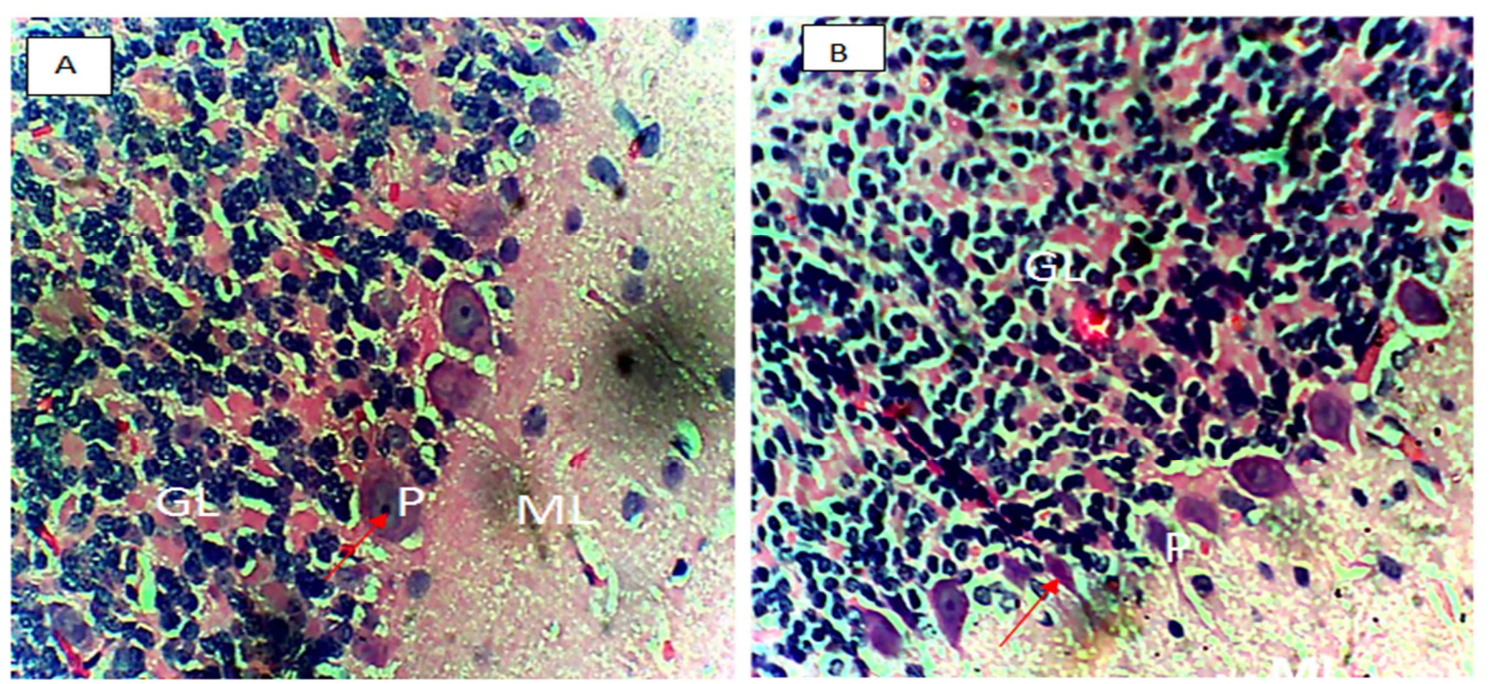

Plate I. Photomicrograph of the histology of the cerebellum of groupA (control) and B (treated with $8.57 \mathrm{mg} / \mathrm{kg}$ of Zidovudine) showing three cerebellar cortical areas; molecular (ML) layer, granular (GL) layer, with an elongated and shrunken Purkinje (P) cells. The purkinje cells, granular cells, basket and starlet cells all appear smaller when compared to the control slide $(A) . H \& E, \times 400$.
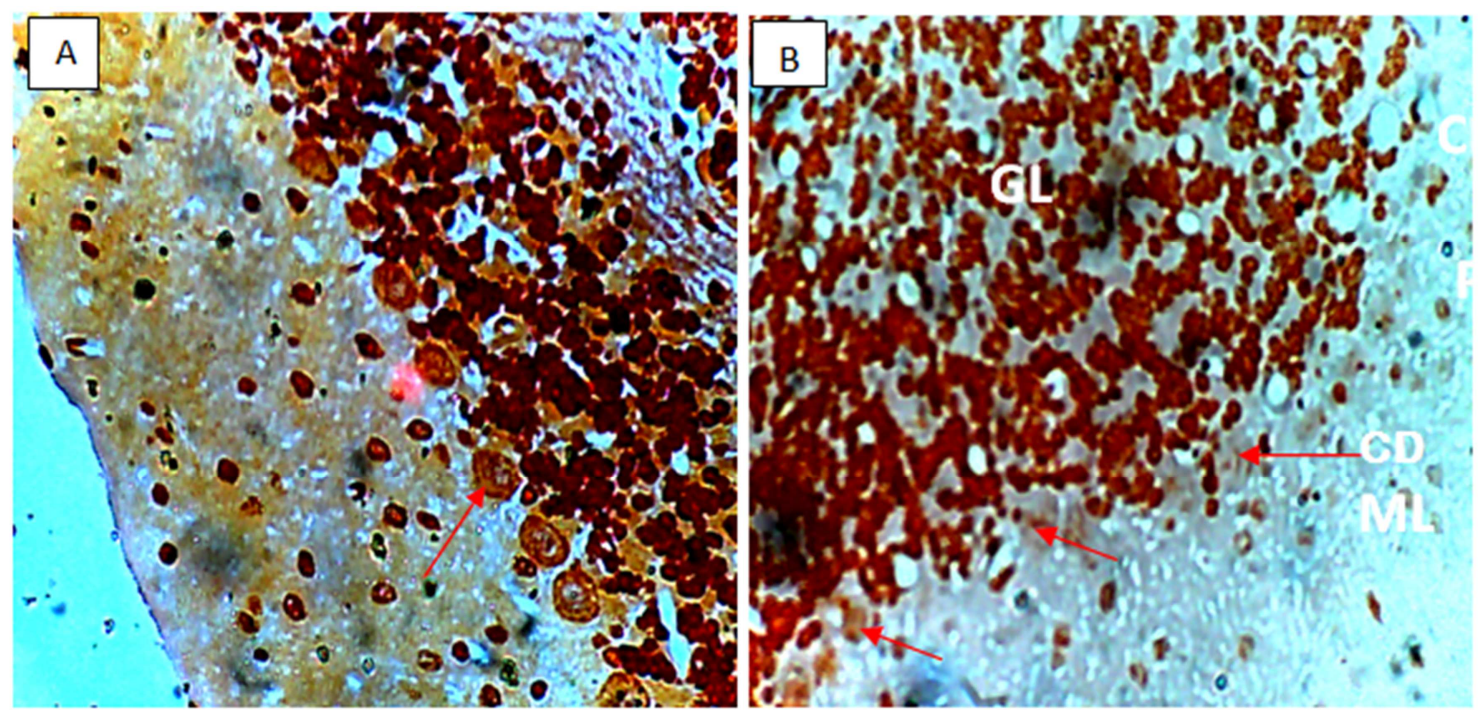

Plate II. Photomicrograph of the histology of the cerebellum of group B treated with $8.57 \mathrm{mg} / \mathrm{kg}$ of Zidovudine showed three cerebellar cortical areas; molecular $(M L)$ layer, granular (GL) layer, with a disrupted, pale and shrunken Purkinje (P) cells (arrow). The Purkinje cells and granular cells appear smaller with cellular degeneration (CD) when compared to the control A, silver stain $\times 400$. 

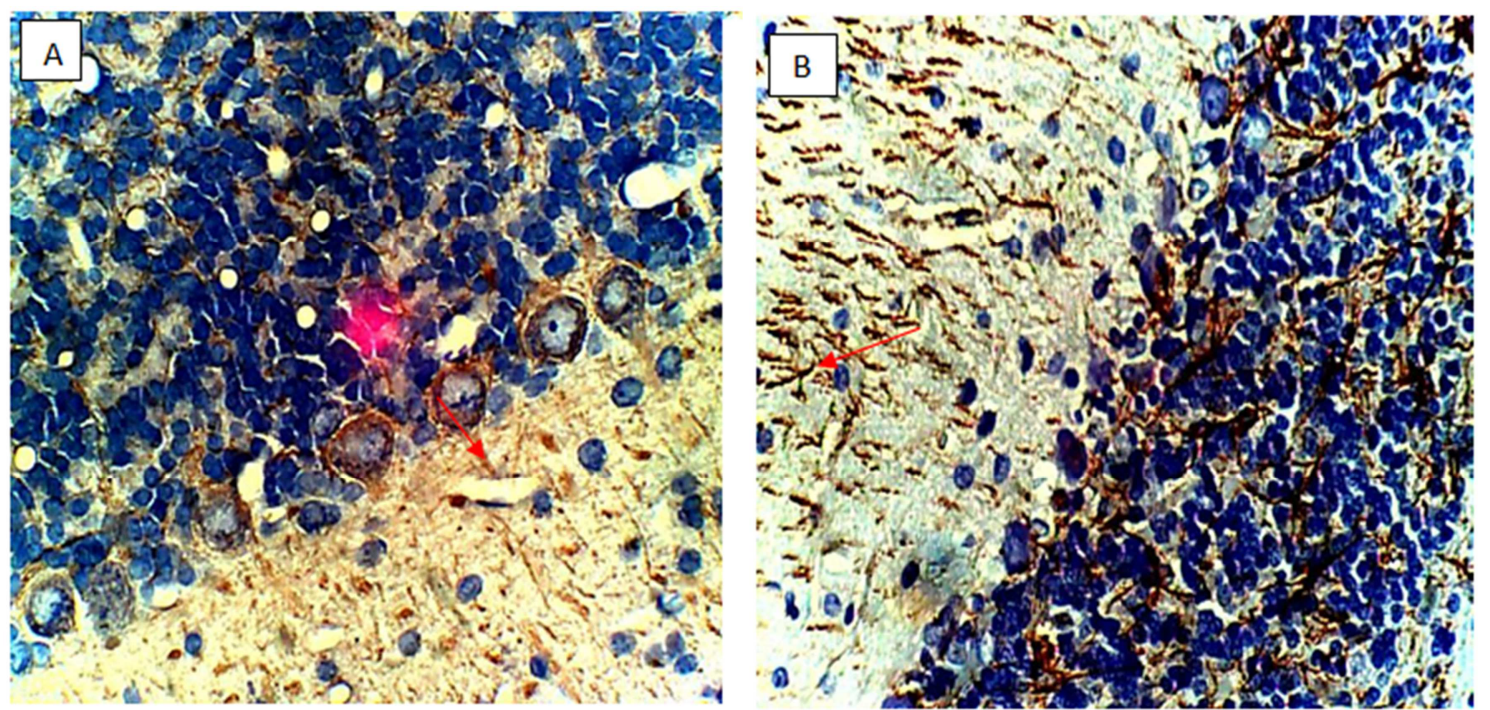

Plate III. Photomicrograph of the histology of the cerebellum of group A control and group B (treated with Zidovudine 8.57mg/kg) showing moderate increased expression of GFAP by astrocytes with expanded processes (gliosis) (arrow) in group B treated with Zidovudine than the control group A GFAP X 400.

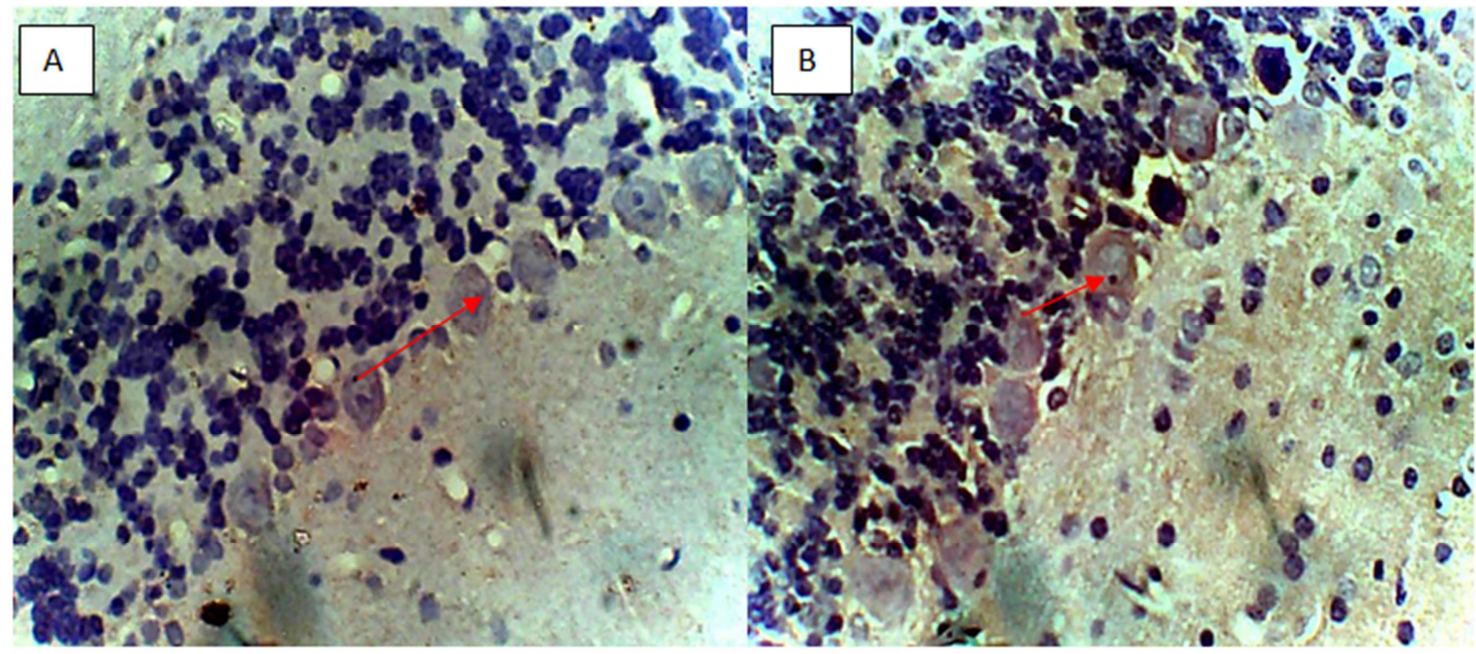

Plate IV. Photomicrograph of the histology of the cerebellum of control A and group B (treated with Zidovudine $8.57 \mathrm{mg} / \mathrm{kg}$ ) showing mild increased expression of NSE (arrow) in group B treated with Zidovudine than the control group A NSE X400.

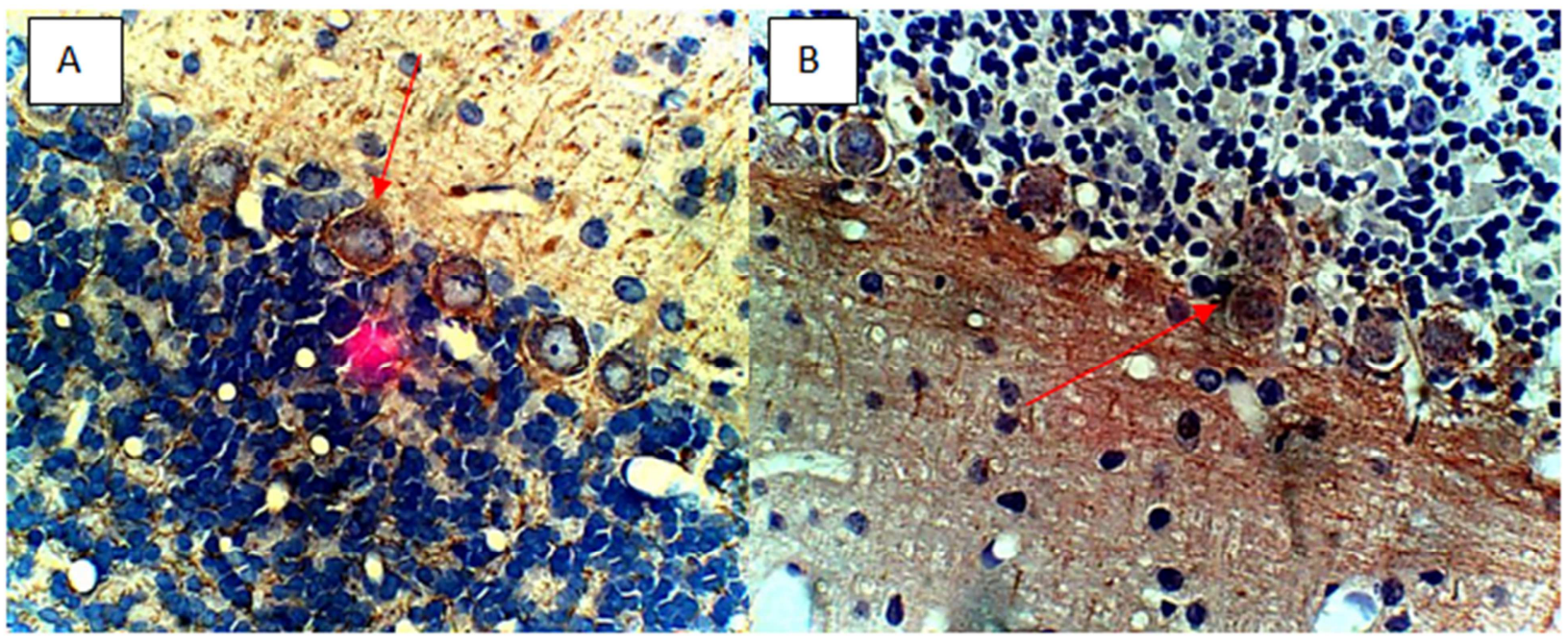

Plate V. Photomicrograph of the histology of the cerebellum of group B treated with Zidovudine $(8.57 \mathrm{mg} / \mathrm{kg}$ showed increased expression of NF and more cellular population stained in group B treated with Zidovudine than the control A NF X 400. 


\section{Discussion}

Zidovudine has been found to be effective, in slowing the progression of AIDS, and can penetrate the blood brain barrier [7]. But there are anecdotal reports of psychiatric symptoms, including mania and depression, in patients treated with zidovudine, even in patients with no previous psychiatric history [8]. The mechanism involved in zidovudine associated psychiatric effects is unknown. Zidovudine also has been associated with seizures, particularly in cases of overdose, which have on rare occasions been fatal [9].

In this study there were distortions on the purkinje cells and granular cells of the cerebellum in the groups treated with Zidovudine, with shrunken cells and degenerative changes in the Purkinje cells, there was atrophy of the granular cells in both the $\mathrm{H}$ and $\mathrm{E}$ and silver stained sections. It was earlier reported by Bialkowska et al. that oxidative damage to nuclear DNA in fetal liver and kidney tissues of pregnant swiss mice and patas monkeys could be caused by zidovudine [19]. Increased level of 8-oxo-2'- deoxyguanosine, a reactive oxygen species, may contribute to the mechanism of transplacental carcinogenesis [19]. Poirier et al. observed incorporation of ZDV into DNA of fetal liver; lung, heart, skeletal muscle, brain, testis and placenta were observed when ZDV was infused to pregnant rhesus monkeys [20]. Researchers frequently use rabbits in toxicity and safety testing of medical devices, vaccines, and drugs. Both mice and rats are heavily used in vaccine and drug research and testing [21]. Wistar rats were used in our study due to availability, low cost of acquisition and ease of ethical approval.

These finding were further supported by immunochemical studies, which showed increased expression of GFAP, NSE and NF by astrocytes and neurons in our study. The increased expressions of these markers indicate cellular injury to the neurons and astrocytes in group B that was administered with Zidovudine. Antibodies against GFAP, the most frequently used astrocyte marker are used to reveal the cytoskeletal structure of the astrocytes [22]. This was demonstrated by the expansion and increased expression of the GFAP marker in our study. Neuronal injury was expressed by increased expressions of NSE and NF in the slides that were administered with zidovudine.

There are numerous reports on mitochondrial alteration in fetus and infants exposed in-utero to ZDV [19-21, 23-24]. This might have been the mechanism of cellular damage in our study. Mechanism of injury could also result from reactive oxygen species from cellular metabolism. Prenatal exposure of animals to zidovudine during pregnancy revealed multiple dysfunctions in the liver kidney ovary and the cerebral cortex [25]. One of the earliest reports observed visual impairment, respiratory and cardiac rhythm disorders, epilepsy, and deterioration of cognitive and psychomotor abilities in children exposed prenatally to ZDV [26]. In another study, mitochondrial DNA was observed to be damaged in liver tissues [27]. In yet another study of prenatal exposure of 40 $\mathrm{mg}$ /day of ZDV in inpatas monkeys showed damage of cerebral mitochondria [28]. Neurobehavioural changes reported by different authors, revealed the cerebral effect of ZDV [29-31]. In- vitro study of brain cells from fetal mouse exposed to ZDV showed slightly more cytotoxic effect as compared to other tissues of the body [32]. Our findings corroborated with the findings of these studies.

The cerebellum is known as the motor control centre, and it is increasingly recognized as contributing to general cognitive processing [33- 38] and emotional control [36-38]. The effect of zidovudine on the cerebellum can lead to motor dysfunction and poor coordination and emotional imbalance. This might further contribute to the poor quality of life of patients with HIV in Nigeria. We recommend that there is urgent need to discover cytoprotective agents that will protect the body against the adverse effect of Zidovudine. The drug should also be prescribed with caution to children.

\section{References}

[1] Wright, K. (1986). AIDS Therapy: First Tentative Signs of Therapeutic Promise. Nature, 323 (6086): 283.

[2] Watts DH. Treating HIV during pregnancy: an update on safety issues. Drug Saf. 2006; 29: 467-490.

[3] Centers for Disease Control and Prevention (CDC). Update: AIDS among women--United States, 1994. MMWR Morb Mortal Wkly Rep 1995; 44: 81-84.

[4] Jeffries, D. J. Zidovudine resistant HIV. British Medical Journal (Clinical research ed.) 1989 ; 298 (6681): 1132-1133.

[5] https://www.pharmgkb.org/pathway/PA165859361 (Retrieved, June1 2015)

[6] Ghodke,Y., Anderson P. L., Sangkuhl, K., Lamba, J., Altman., R. B. and Klein, T. E. PharmGKB summary: zidovudine pathway. Pharmacogenetics and Genomics 2012; 22:891-894

[7] Blum, M., Good, S., Liao, S. and de Miranda, P. Pharmacokinetics and Bioavailability of Zidovudine in Humans. American Journal of Medicine, 1989; 85: 189-194.

[8] Maxwell, S., Scheftner, W., Kessler, H. and Busch, K. Syndrome Associated With Zidovudine Treatment [Letter]. Journal of American Medical Association, 1988; 259: 3406-3407

[9] Hagler, D. and Frame, P. Azido thymidine neurotoxicity [Letter]. Lancet,1986; 2: 1392-1393.

[10] http://www.aidsmap.com/resources/treatmentsdirectory/ (Retrieved online on 7/6/14)

[11] Cronkite, E. P. and Bullis, J. In vivo toxicity of 3'-azido-3'-deoxythymidine (AZT) on $\mathrm{CBA} / \mathrm{Ca}$ mice. Int. J. Cell Cloning, 1990; 8, 332-345

[12] Bogliolo, G., Lerza, R., Mencoboni, M., Flego, G., Gasparini, L. and Pannacciulli, I. Hematoxic effects on mice of combined administration of azidothymidine and acyclovir. Exp. Hematol.,1991; 19, 838-841 
[13] Thompson, M. B., Dunnick, J. K., Sutphin, M. E., Giles, H. D., Irwin, R. D. and Prejean, J. D. Hematologic toxicity of AZT and ddC administered as single agents and in combination to rats and mice. Fundam. appl. Toxicol.,1991; 17, 159-176

[14] Scheding, S., Media, J. E. and Nakeff, A. Acute toxic effects of 3'-azido-3'-deoxythymidine (AZT) on normal and regenerating murine hematopoiesis. Exp. Hematol., 1994; 22, 60-65

[15] Omar, R. F., Gourde, P., Desormeaux, A., Tremblay, M., Beauchamp, D. and Bergeron, M. G. (1996) In vivo toxicity of foscarnet and zidovudine given alone or in combination. Toxicol. appl. Pharmacol., 139, 324-332

[16] Inoue, T, Cronkite, E. P., Hirabayashi, Y, Bullis, J. E., Jr, Mitsui, $H$. and Umemura, T. Lifetime treatment of mice with azidothymidine (AZT) produces myelodysplasia. Leukemia, $1997 ; 3,123-127$

[17] Rao, G. N., Lindamood, C. Heath, J. E., Farnell, D. R, and Giles, H. D. Subchronic toxicity of human immunodeficiency virus and tuberculosis combination therapies in $\mathrm{B} 6 \mathrm{C} 3 \mathrm{~F} 1$ mice. Toxicol. Sci., 1998; 45, 113-127

[18] Olivero, O. A., Anderson, L. M., Diwan, B. A., Haines, D. C., Harbaugh, S. W., Moskal, T. J., Jones, A. B., Rice, J. M., Riggs, C. W., Logsdon, D., Yuspa, S. H. and Poirier, M. C. Transplacental effects of 3'-azido-2',3'-dideoxythymidine (AZT): Tumorigenicity in mice and genotoxicity in mice and monkeys. J. natl Cancer Inst.,1997; 89, 1602-1608

[19] Bialkowska, A., Bialkowski, K., Gerschenson, M., Diwan, B. A., Jones, A. B. et al. Oxidative DNA damage in fetal tissues after transplacental exposure to 3'-azido-3'-deoxythymidine (AZT). Carcinogenesis.2000; 21: 1059-1062.

[20] Poirier, M. C., Patterson, T. A., Slikker, W. Jr and Olivero, O. A Incorporation of 3'-azido-3'-deoxythymidine (AZT) into fetal DNA and fetal tissue distribution of drug after infusion of pregnant late-term rhesus macaques with a human-equivalent AZT dose. J Acquir Immune Defic Syndr. 1999; 22: 477-483.

[21] http://www.neavs.org/research/biomedical retrieved online on the $6^{\text {th }}$ of August 2015

[22] Braddy TB, Siegel G J, Albers R.W and Price DL. BasicNeurochemistry Principles of Molecular Medical Neurobiology $8^{\text {th }}$ ed. Wyman USA, Academy press Elservier, $2012 ; 114,815$

[23] Meng, Q., Fasco, M. J., Bellisario, R., Kaminsky, L., Pass, K. A et al. Plasma and cellular markers of 3'-azido-3'deoxythymidine metabolism as indicators of DNA incorporation of 3'-azido-3'-deoxythymidine metabolism as indicators of DNA incorporation of 3'-azido-3'deoxythymidine in cord blood lymphocytes from infants exposed in utero. Environ Mol Mutagen.2001; 37: 53-58.

[24] Slamenová, D., Horváthová, E. and, Bartková, M. Nature of DNA lesions induced in human hepatoma cells, human colonic cells and human embryonic lung fibroblasts by the antiretroviral drug 3'-azido-3'-deoxythymidine. Mutat Res.2006; 593: 97-107.
[25] Chongtham, R., Bhattacharyya, A. and Kumar, M. Histopathological Changes in Multiple Fetal Tissues Exposed In-Utero to Zidovudine Chongtham J AIDS Clin Res 2014, $5: 11$

[26] Blanche, S., Tardieu, M., Rustin, P., Slama, A., Barret, B., et al., Persistent mitochondrial dysfunction and perinatal exposure to antiretroviral nucleoside analogues. Lancet. 1999; 354: 1084-1089.

[27] De la Asunción, J. G., del Olmo, M. L., Sastre, J., Pallardó, F. V. and Viña, J. Zidovudine (AZT) causes an oxidation of mitochondrial DNA in mouse liver. Hepatology. 1999; 29: 985-987.

[28] Ewings, E. L., Gerschenson, M., St Claire, M. C., Nagashima, K., Skopets, B. et al. Genotoxic and functional consequences of transplacental zidovudine exposure in fetal monkey brain mitochondria. J Acquir Immune Defic Syndr. 2000; 24: 100-105.

[29] Calamandrei, G., Venerosi, A., Branchi, I. and Alleva E. Effects of prenatal zidovudine treatment on learning and memory capacities of preweanling and young adult mice. Neurotoxicology 1999; 20: 17-25

[30] Venerosi, A., Cirulli, F., Lil'p, I. G., Fiore, M., Calamandrei, G. et al. Prolonged perinatal exposure to AZT affects aggressive behaviour of adult CD-1 mice. Psychopharmacology (Berl) 2000; 150: 404-411.

[31] Rajlakshmi, C., Trigunayat, A., Bhattacharyya, A. and Pandey BL Neurobehavioural profile of F1 and F2 generation mice following one stage Zidovudine exposure through pregnancy and lactation. Annals of Neurosciences. 2008;15: 69-74.

[32] Sieh, E., Coluzzi, M. L., Cusella, D., Angelis, M. G., Mezzogiorno, A., Floridia, M. et al. The effects of AZT and DDI on pre- and postimplantation mammalian embryos: an in vivo and in vitro study. AIDS Res Hum Retroviruses. 1992; 8: 639-649.

[33] Diamond, A. Close interrelation of motor development and cognitive development and of the cerebellum and prefrontal cortex. Child Dev. 2000;71(1):44-56

[34] Baillieux, H., Smet, H. J., Paquier, P. F., De Deyn, P. P. and Marien P. Cerebellar neurocognition: Insights into the bottom of the brain. Clin Neurol Neurosurg. 2008;110(8):763-73.

[35] Ito M. Movement and thought: identical control mechanisms by the cerebellum. Trends Neurosci. 1993;16(11):448-50

[36] Fiez, J. A. Cerebellar contributions to cognition, Neuron, 1996; 16: 1 , pp. $12-15$,

[37] Chizhikov, V. and. Millen, K. J. Development and malformations of the cerebellum in mice, Molecular Genetics and Metabolism, 2003; 80 (1-2) 54-65,

[38] Kiernan, J. (2009) The Human Nervous System. Ontario, Canada: Lippincott William and Wilkins. Chapter18, Page 267274. 